\title{
Women with overweight, mixed hyperlipidemia, intolerance to glucose and diastolic hypertension
}

\author{
Ruth-Maria Korth \\ Research in General and Natural Medicine FiDA ${ }^{\mathrm{R}}$, Munich, Germany; fida@i-dial.de
}

Received 16 December 2013; revised 23 January 2014; accepted 31 January 2014

\section{ABSTRACT}

Primarily healthy women who attended a practice of General Medicine were examined and coded data were evaluated using two statistical methods ( $n=248$, aged $36 \pm 14$ years). It was found that participants with LDL-related (mixed) hyperlipidemia showed higher blood pressure, a higher proportion of alcohol problems and/or smoking compared to normolipidemic women ( $p$ $\leq \mathbf{0 . 0 5}$ ). These hyperlipidemic women who reported alcohol problems and/or smoking more often showed proteinuria and/or hematuria, rise of LDL/HDL, critical fasting blood glucose and lower HDL-cholesterol compared to hyperlipidemic women reporting healthy lifestyle ( $p \leq$ 0.05). Likewise, high triglycerides were associated with rise of blood pressure and intolerance to glucose $(p \leq 0.05)$ and also with elevated total cholesterol. Alcohol-related hypertriglyceridemia overlapped with diastolic hypertension, rise of body weight and urine pathology, lowering of HDL-cholesterol and critical fasting blood glucose. The motivating message was that women with mixed hyperlipidemia and healthy lifestyle had functionally renal endothelium and healthy HDL-related baseline measures. Altogether, LDLrelated hyperlipidemia and/or high triglycerides were correlated with diastolic hypertension whereby critical alcohol consumption declined renal endothelium and lowered HDL-cholesterol implicating baseline strategies to neutralize ear- ly risk factors.

\section{KEYWORDS}

Combined Telemedical Care; Overweight; Mixed Hyperlipidemia; Intolerance to Glucose; Hypertension; Renal Endothelium; Dyslipidemia; Women's Health

\section{INTRODUCTION}

Baseline measures were confidentially invented here with primarily healthy women who initially attended a General Medicine practice. Critical lipid profiles of middle-aged participants were evaluated testing blood pressure, morning urines, HDL-cholesterol and fasting blood glucose. The clinical study program was based on original science because alcohol-related ether phospholipids are carried by lipoproteins or serum albumin and interact with very high affinity binding sites of human endothelial cells [1-4].

Evidence has been provided with male study groups that high triglycerides and self-reported alcohol use trigger hypertension and decline renal endothelium in the absence of diabetes, inflammations or urological infections [5,6]. Foreign population-based studies correlate urinary albumin with late cardiovascular disorders of elderly persons $[7,8]$. Many prospective studies have established the major risk factors for arterial disorders consisting of hypercholesterolemia, hypertension and type 2 diabetes mellitus [8,9]. In addition, elderly persons with type 2 diabetes often smoke and smoking persons often have inflammatory disorders [10-12].

The overall objective of this study was to find early decline of renal endothelium barriers and/or silent diastolic hypertension of middle-aged women on the basis of initial biomarkers. Primarily healthy women were confidentially invented here to determine relevant midlife risk factors.

Swedish women with thickening of the arterial intima are correlated with autoantibodies against transformed LDL-associated phospholipids while small vessel disease was not tested [13]. Medical studies further disclose that women with hypertension and proteinuria are at direct risk for kidney disorders predicting higher mortality as shown in a 24-year follow-up study in Sweden [14]. Male cohorts of the Karolinska University show that autoantibodies against transformed LDL-associated phospholipids are correlated with carotid intima thickness, hypertension and hyperinsulinemia whereby the followup studies subsequently show late arterial disorders of men at risk [15,16]. Autoantibodies against cardiolipin or transformed LDL-related phospholipids predict higher mortality of elderly persons who suffer of late athero- 
sclerosis [17]. Diagnostic antibodies against benzodiazepine-sensitive GABA receptors recognize inflammatory monocytes in vulnerable arterial plaques [18]. Endothelial cells express receptors for alcohol-related ether phospholipids whereby benzodiazepine derivatives and Ginkgolides are specific antagonists [1-3,19,20].

This clinical study looked more carefully at metabolic profiles of apparently healthy women to better protect female endothelium barriers and to improve the distribution of cholesterol on the basis of lipoproteins (LDL/ HDL) whereby the relationship was also tested between serum albumin and triglycerides (Alb/Trig). Serum albumin was invented here as native serum albumin binds alcohol-related ether phospholipids and protects human cells in general [1-4,21-26]. The present clinical standard procedures tested these plasma compartments [5,6,2125].

Low fat dairy products were recommended comprising healthy albumin to neutralize moderate alcohol consumption [26]. However, some dairy products comprise glycation end products and/or glycated albumin so that dietary recommendations inform about these critical ingredients $[27,28]$. Food with saturated fat and/or adverse phospholipids trigger unfavorable uptake of lipids forming then unhealthy lipid mediators and dysfunctional lipases, phospholipases by preference in the presence of critical alcohol consumption [reviewed in 29-31].

Classical clinical studies show that obese adolescents have multiple risk factors and often show arterial lesions at 21 to 39 years of age [32]. Obesity-related nutrition guidelines advise reduced uptake of energy, sodium, adverse carbohydrates and cessation of smoking [33]. Obese women have to perceive that ether lipids are present in adipocytes [34]. The present phenotype ranking moved forward to determine the relevant risk profiles of apparently healthy women who had overweight/obesity in the presence of mixed hyperlipidemia, intolerance to glucose and/or hypertension (OMIH).

Known antihypertensive strategies recommend reducing uptake of sodium and to ceding smoking whereby low fat dairy products and fresh vegetables are advised in general [35]. It is commonly known that hypertension is an important predictor of stroke and/or age-related vascular dementia [36]. Nicotine cessation is recommended on the basis of experiments showing putative nonenzymatic peroxidation of phosphatidylcholine and impaired lipases, phospholipases and acetylhydrolases [35,37-39].

German guidelines oppose risky alcohol consumption because alcoholic fatty liver disease is a locally relevant problem [6,21,40]. Adverse alcohol consumption forms ether phospholipids, chemically 1-alkyl-2-acyl-(shortchain)-sn-glycero-phosphocholines (LA-paf) and alcohol-related rise of triglycerides shows additive hypertensive effects of men at risk $[6,21,31]$. The background art about age-related hypertension is included by citation [reviewed in 41]. Rise of diastolic blood pressure was invented here with primarily healthy middle-aged women who had critical lipid profiles and/or who reported an unhealthy lifestyle behavior.

Valid guidelines advise healthy food with reduced uptake of cholesterol and saturated fat [37]. Lipid lowering pharmacotherapy is considered when hypercholesterolemic persons cannot change risk-related problems [37,42]. European lipid lowering guidelines recommend lowering of LDL-cholesterol $(70-100 \mathrm{mg} / \mathrm{dl})$ in the presence of two risk factors selected from the group consisting of elevated cholesterol, high triglycerides, low HDL-cholesterol, hypertension, smoking, obesity and/or age-related diabetes mellitus [37,42]. A genome-wide associated program provides evidence that LDL-cholesterol is the major risk factor of arterial problems whereby statins successfully antagonize adverse cholesterol-related disorders $[42,43]$. Combined lipid lowering pharmacotherapy with statins and ezetimibe antagonizes formation and uptake of cholesterol to inhibit thickening of arterial intima-media prediciting stroke and cardiovascular events $[37,44]$. Statins protect against the injurious outcome of high LDL-cholesterol in the presence of type 2 diabetes mellitus [45]. Original science shows that LDL-particles form and express adhesion molecules, phospholipases and acetylhydrolases on outer membranes whereby VLDLparticles make human endothelial cells sticky [2,20,25].

There are unclear reports in view of exporting cholesterol efflux and/or human cholesterol transfer proteins [reviewed in 46]. It is unclear why nicotinic acids fail benefit although nicotinic acids increase the level of HDLcholesterol testing elderly persons with arterial disorders [47]. Other reports distinguish HDL-cholesterol and cholesterol efflux using blood macrophages of elderly persons [48]. Altogether, combined pharmacotherapy specifically lowers LDL-cholesterol while dysfunctional HDLparticles are not fully repaired $[44,47]$.

Medical testing was combined with monitoring of blood pressure of consenting women as men with high triglycerides are correlated with hypertension [6,21,31]. Guidelines combine medical supervision with home monitoring of blood pressure [49]. This study tested at baseline blood pressure, morning urines and metabolic profiles in the medical practice to determine lipid-related hypertension among primarily healthy persons whereby inflammatory disorders were excluded [6,21].

Coded lipid profiles were evaluated testing the cholesterol ratio LDL/HDL, HDL-cholesterol, triglycerides, serum albumin and fasting blood glucose to gain knowledge about the HDL-related defense system of relatively young women. The HDL-related background knowledge of skilled persons is included by citation [reviewed in 46]. Background science suggests that nonenzymatic peroxi- 
dation of phospholipids modulate lecithin-cholesterolacyl-transferases (LCAT) which impairs HDL-related cholesterol efflux [50,51]. In addition, glycated HDLrelated apoproteins of diabetic persons trigger dysfunction of HDL-particles so that diabetic persons need early pharmacotherapy [51]. It is known that healthy exercising triggers cholesterol efflux as commonly recommended baseline strategy against dysfunctional HDL-particles [52].

Additive risk profiles were invented here with primarily healthy women on the basis of overweight/obesity, mixed hyperlipidemia, intolerance to glucose and/or hypertension (OMIH-syndrome). Personal history was enrolled whereby initially reported alcohol problems and/or smoking were anonymously documented and a relevant proportion was found. Self-testing of morning urines and blood pressure was implemented then to improve critical dietary habits of middle-aged women who had to perceive their direct risk for hypertension.

\section{METHODS}

\subsection{Objective, Recruitment, Study Population}

Primarily healthy women were initially examined in a Bavarian Practice of General Medicine (248 out of 1108, aged $36 \pm 14$ years). Informed written consent was provided in accordance with the local ethical authority (BLÄK-EK, No. 02088, No. 07026). Biomarkers of nonpregnant women were coded and evaluated.

Women were not recruited who had at least one of the below mentioned disorders $(n=843)$. Complete blood counting excluded hematological or inflammatory problems. C-reactive proteins were tested to exclude inflammatory disorders $(\mathrm{CRP} \leq 0.6 \mathrm{mg} / \mathrm{dl})$. Thyroid hormones were in the normal range (TSH: $0.3-2.5 \mu \mathrm{U} / \mathrm{ml}$ ). Known diabetes mellitus was initially excluded (with HbA1c $\leq$ $6 \%$ ). Addictive alcohol disorders were excluded on the basis of personal history and liver values [5,31]. Urological infections and renal disorders were initially excluded with indicated urine testing and plasma creatinine $(\leq 1.1$ $\mathrm{mg} / \mathrm{dl})$. Women with liver cirrhosis, hepatitis and/or alcoholic steatohepatitis were not recruited (SGPT, SGOT35 $\mathrm{U} / \mathrm{ml})$. Patients with known cerebral or neoplastic disorders were excluded. Women were not included who attended the practice only for vaccination or drug therapy.

\subsection{Subgroups of Female Baseline Measures}

Baseline measures were enrolled of healthy primary care women. Subgroups were formed and numbered data were anonymously evaluated.

Subgroup 1: Body mass index classified women with normal weight $\left(\mathrm{BMI}_{\mathrm{n}}:<25 \mathrm{~kg} / \mathrm{m}^{2}, \mathrm{n}=191\right)$, overweight $\left(\mathrm{BMI}_{1}: \geq 25 \mathrm{~kg} / \mathrm{m}^{2}, \mathrm{n}=31\right)$ or obesity $\left(\mathrm{BMI}_{2}: \geq 29 \mathrm{~kg} / \mathrm{m}^{2}\right.$, $\mathrm{n}=26$ ).

Subgroup 2: Self-reported alcohol consumption was documented in the medical practice $(\geq 20 \mathrm{~g}$ ethanol per day, 35 out of 248 (14\%), aged $38 \pm 12$ years). German alcohol-related guidelines were considered to classify risky, critical, heavy alcohol consumption ( $\geq 20 \mathrm{~g}, \geq 40 \mathrm{~g}$, $\geq 60$ g ethanol per day) [40]. Self-reported alcohol problems and/or risky uptake of beer were summarized stating "alcohol problems". Nonsmoking women who disowned daily alcohol consumption were characterized stating "healthy lifestyle".

Subgroup 3: Women were selected on the basis of fasting lipid profiles to characterize the outcome of high triglycerides (trig $\geq 170 \mathrm{mg} / \mathrm{dl}$, aged $41 \pm 16$ years, $\mathrm{n}=$ 38 ), high total cholesterol (chol $\geq 200 \mathrm{mg} / \mathrm{dl}$, aged $40 \pm$ 19 years, $n=42$ ) or high LDL-cholesterol (LDL-C $\geq 150$ $\mathrm{mg} / \mathrm{dl}$, aged $35 \pm 15$ years, $\mathrm{n}=28$ ) or of normolipidemia $(\mathrm{n}=45$, aged $31 \pm 11$ years, $1 \mathrm{mg} / \mathrm{dl}$ cholesterol is about $26 \mu \mathrm{mol} / \mathrm{mg})$.

The major higher-risk subgroup was selected with "LDL-related mixed hyperlipidemia" (26 out of 248: total chol $\geq 220 \mathrm{mg} / \mathrm{dl}$, LDL-C $\geq 150 \mathrm{mg} / \mathrm{dl}$, trig $\geq 170 \mathrm{mg} / \mathrm{dl}$, aged $35 \pm 15$ years) to be compared with normolipidemic participants. Multivariate analysis determined then the relationship between indicated risk factors and symptoms.

A relationship between triglycerides and intolerance to glucose was also evaluated (IGTT: $1 \mathrm{hpp} \geq 140 \mathrm{mg} / \mathrm{dl}$, LDL-C: $197 \pm 35 \mathrm{mg} / \mathrm{dl}, \mathrm{n}=22$, aged $41 \pm 15$ years). Symptoms were characterized on the basis of high triglycerides and/or self-reported alcohol consumption (AHA, 16 out of 38) or of nonalcoholic (NA-) hypertriglyceridemia (22 out of 38). Women with alcohol-related $(n=16)$ versus nonalcoholic hyperlipidemia (NA: $\mathrm{n}=10$ ) were compared.

Next, HDL-cholesterol characterized participants (96 out of 248, aged $38 \pm 16$ years) who were further classified either on the basis of healthy (HDL-C $\geq 60 \mathrm{mg} / \mathrm{dl}$, 50 out of 96 (52\%) aged $39 \pm 14$ years) or with relatively low HDL-cholesterol (HDL-C $<60 \mathrm{mg} / \mathrm{dl}$, 46 out of 96 (48\%), aged $35 \pm 15$ years). Dyslipidemia was determined here with elevated LDL/HDL $(\geq 3.0)$ and relatively low HDL-cholesterol $(<60 \mathrm{mg} / \mathrm{dl})$. The ratio of serum albumin to triglycerides was calculated in the practice (Alb/Trig).

The proportion of smoking participants was determined and these women were also characterized on the basis of HDL-cholesterol (60 out of 248).

\subsection{Study Program}

Primarily healthy women were examined who attended 
the medical practice for the first time. Data were scored in the same form since 1990 whereby initial age, blood pressure, morning urines, metabolic profiles, self-reported alcohol use, smoking and family history were confidentially enrolled.

Blood pressure of women was initially tested in the practice after 10 minutes of rest stating prehypertension $(\geq 135 / \geq 85 \mathrm{mmHg}$ ) or hypertension $(\geq 140 / \geq 90 \mathrm{mmHg})$ in view of valid guidelines (www.heart.org/hbp).

Venous blood was taken to measure plasma markers in certified laboratories. Serum albumin was also measured (electrophoresis Elephanscan/Fractoscan, Merck: 1.5\% variation). The ratio of serum albumin to triglycerides (Alb/Trig) was calculated in the FiDA-practice [5,6,21, 26].

Morning urine samples were initially tested in the practice to determine proteinuria, albuminuria and unclear hematuria (Combur 9, Roche, Switzerland). Albuminuria (Microbumin, Bayer, Germany). Proteinuria was initially confirmed with urinary protein analysis and certified clinical laboratories excluded pathological proteins (not shown here). Urine microscopy confirmed red cells and excluded pathological casts. Unclear microhematuria (24 of 248) and proteinuria (15 out of 248) were stated as "urine pathology" (without leukocyturia).

Individual problems were discussed in the practice and informed women provided written consent. Home monitoring and examinations in the medical practice determined critical risk profiles. Official healthcare informations were offered in the practice (www.heart.org/hbp). Telemedical monitoring motivated participants to test blood pressure, body weight, morning urines using coded self-control documentations. Telemedical presentations inform about healthy liquids without alcohol and recommend certified low fat milk products because benefit was shown with coded case reports (www.fida-aha.com, www.fidabus.com) [26,53-56].

Women at risk were reexamined in the practice at least once a year and medical counseling of experts was included (not shown).

\subsection{Statistical Methods}

Significant and relevant measures were indicated ( $\mathrm{p} \leq$ 0.05, $\mathrm{p} \leq 0.1$, means $1 \pm$ S.D.). Baseline measures were scored since 1990 in the same form and timely stable subgroups were compared to controls [6].

In short, least square estimates for means were used to calculate standard deviations of blinded data from a generalized linear model (GLM, SAS-V8.2, PROC GLM, estimates, Augsburg, Germany). Tukey's tests were used for pairwise comparisons, controlling type I error rate. The relationship between risk factors and/or symptoms was then evaluated with multivariate analysis by means of a multiple logistic regression analysis (SAS V8.2, PROC LOGIST).

\subsection{Summary}

The medical examination was performed at baseline in the General Medicine practice and telemedical monitoring was then implemented with consenting women using coded self-control documentation (www.fida-aha.com).

\section{RESULTS}

\subsection{Characteristics of the Study Group Testing Blood Pressure}

Baseline measures of healthy women were invented here in the General Medicine practice. The majority of the primary care women showed normal body weight, healthy baseline measures and reported healthy lifestyle (Table 1 , see $\mathrm{BMI}_{\mathrm{n}}$ ). In a broad overview, a relevant proportion of participants tended to critical body weight and showed apparently inhomogenous risk factors to be distinguished hereinafter $\left(\mathrm{BMI}_{1+2}: 23 \%\right.$ of 248 , Table 1$)$.

Two time-related divisions showed stable characteristics on the basis of self-reported alcohol problems or elevated triglycerides (Table 2, AHA: 14\% of 248). The proportion of smoking participants increased in the second study group (B: 24\% of 248, $17 \pm 9$ cigarettes/day versus $A, p=0.003)$. Overall, a relevant proportion of women had critical diastolic blood pressure at baseline (35\% of 248, $137 \pm 25 / 96 \pm 7 \mathrm{mmHg}$ ). Elevated blood pressure of obese women did not change during the long screening period since 1990 (see subgroup 1, Tables 1 and 2). However, obese women recently often disowned daily alcohol consumption showing then normal morning urines so that statistical evaluation of obesity-related lifestyle behavior was limited.

The significant rise of diastolic blood pressure was found with obese women compared to women with normal weight ( $\mathrm{p}<0.05$ : $\mathrm{BMI}_{2}$ versus $\mathrm{BMI}_{\mathrm{n}}$, Table 1 ). No significant rise of blood pressure was found comparing overweight and normal weight $\left(\mathrm{BMI}_{1}\right.$ versus $\mathrm{BMI}_{\mathrm{n}}$, Table 1). No significant rise of blood pressure was reached comparing overweight and obesity $\left(\mathrm{BMI}_{1}\right.$ versus $\mathrm{BMI}_{2}$, Table 1). The warning message was that obesity was a direct risk factor for hypertension.

\subsection{Subgroup 2: Overweight, Urine Pathology, Alcohol Problems}

Women with overweight were characterized and these women often reported alcohol problems and/or smoking (Table 1, see $\mathrm{BMI}_{1}$ ). Women with overweight reporting alcohol problems often showed urine pathology (Figure 1). Likewise, women with critical alcohol consumption often had overweight and half of these risky participants 
Table 1. Initial LDA-related hyperlipidemia or obesity showed higher blood pressure than controls (LDL-Trig vs Norm-LIP, BMI 2 vs $\mathrm{BMI}_{\mathrm{n}}, \mathrm{p} \leq$ 0.05). High triglycerides, intolerance to glucose, alcohol use overlapped (Trig, IGTT, 1 hpp: $185 \pm 50 \mathrm{mg} / \mathrm{dl}$, AHA).

\begin{tabular}{|c|c|c|c|c|c|c|c|c|}
\hline Variables: & $\mathrm{BMI}_{\mathrm{n}}($ No. 1) & $\mathrm{BMI}_{1}$ (No. 1) & $\mathrm{BMI}_{2}$ (No. 1) & $\begin{array}{l}\text { LDL + Trig } \\
\text { (No. 3a) }\end{array}$ & $\begin{array}{l}\text { Norm Lip } \\
\text { (No. 3b) }\end{array}$ & Trig (No. 3c) & IGTT (No. 3c) & AHA (No. 2) \\
\hline number out of 248 & $\mathrm{n}=191(77 \%)$ & $\mathrm{n}=31(13 \%)$ & $\mathrm{n}=26(10 \%)$ & $\mathrm{n}=26(10 \%)$ & $\mathrm{n}=45$ & $\mathrm{n}=38(15 \%)$ & $\mathrm{n}=22(9 \%)$ & $\mathrm{n}=35(14 \%)$ \\
\hline BMI, kg/m² & $21 \pm 4$ & $27 \pm 1$ & $31 \pm 6$ & $28 \pm 13$ & $23 \pm 5$ & $26 \pm 5$ & $28 \pm 4$ & $26 \pm 5^{* *}$ \\
\hline Age, years & $36 \pm 20$ & $40 \pm 18$ & $35 \pm 14$ & $35 \pm 15$ & $31 \pm 11$ & $41 \pm 16$ & $41 \pm 15$ & $38 \pm 12$ \\
\hline Total cholesterol mg/dl & $169 \pm 52$ & $206 \pm 44$ & $212 \pm 39$ & $250 \pm 33$ & $167 \pm 23$ & $235 \pm 43$ & $221 \pm 56$ & $200 \pm 31$ \\
\hline LDL-C mg/dl & $131 \pm 43$ & $155 \pm 53$ & $153 \pm 54$ & $164 \pm 63^{* *}$ & $112 \pm 24$ & $163 \pm 39$ & $167 \pm 54$ & $153 \pm 40$ \\
\hline HDL-C mg/dl & $65 \pm 19$ & $56 \pm 16$ & $60 \pm 19$ & $55 \pm 15$ & $66 \pm 17$ & $57 \pm 16$ & $58 \pm 29$ & $60 \pm 14$ \\
\hline Fast. Glucose mg/dl & $83 \pm 12$ & $86 \pm 11$ & $88 \pm 14$ & $93 \pm 14^{*}$ & $84 \pm 11$ & $89 \pm 9$ & $86 \pm 16$ & $82 \pm 11$ \\
\hline Syst. RR mmHg & $117 \pm 17$ & $132 \pm 21$ & $138 \pm 20$ & $139 \pm 29^{* *}$ & $120 \pm 15$ & $135 \pm 29^{* *}$ & $135 \pm 29$ & $133 \pm 10$ \\
\hline Diast. RR mmHg & $82 \pm 9$ & $86 \pm 11$ & $92 \pm 23^{* *}$ & $92 \pm 13^{* *}$ & $82 \pm 9$ & $88 \pm 16^{* *}$ & $89 \pm 16$ & $88 \pm 17$ \\
\hline Triglycerides mg/dl & $110 \pm 57 \%$ & $145 \pm 88$ & $166 \pm 94$ & $254 \pm 73$ & $90 \pm 30$ & $235 \pm 74$ & $238 \pm 125$ & $144 \pm 78$ \\
\hline Smoking & $10 \%$ of 191 & $26 \%$ of 31 & $19 \%$ of 26 & $35 \%$ of $26^{* *}$ & $17 \%$ of 45 & $47 \%$ of 38 & $36 \%$ of 22 & $37 \%$ of 35 \\
\hline $\mathrm{AHA} \geq 20 \mathrm{~g}$ ethanol/day & $5 \%$ of 191 & $29 \%$ of 31 & $19 \%$ of 26 & $46 \%$ of $26^{* *}$ & $1 \%$ of 45 & $34 \%$ of 38 & $9 \%$ of 22 & elected \\
\hline Urine Pathology & $8 \%$ of 191 & $39 \%$ of 31 & $19 \%$ of 26 & $31 \%$ of $26^{* *}$ & $18 \%$ of 45 & $29 \%$ of $38^{*}$ & $9 \%$ of 22 & $54 \%$ of $35^{* *}$ \\
\hline
\end{tabular}

Diastolic hypertension was found with LDL-related hyperlipidemia, high triglycerides, intolerance to glucose vs controls ( 3 a vs $3 b)$. Hypertension (42 of 248 (19\%), urine pathology $(n=46,19 \%)$ or critical fasting blood glucose $(n=57,23 \%)$ were relevant as well. For details see text applied to indicated subgroups No. 1 - 3. Values are means \pm 1 S.D. ( ${ }^{* * *} \mathrm{p} \leq 0.05 ; \mathrm{p} \leq 0.1$, 3a, 3c vs $\left.3 b\right)$.

Talbe 2. Time-table showed unchanged triglycerides or alcohol problems (AHA, A: 1990-1999, n = 160 vs B: $2000-n=88$ out of 248) Smoking increased (B vs A: $\mathrm{p}=0.003$ ) and the obesity division showed then inhomogenous lifestyle problems $\left(\mathrm{BMI}_{2}\right)$.

\begin{tabular}{|c|c|c|c|c|c|c|c|c|}
\hline \multirow{2}{*}{$\begin{array}{c}\text { Variables: } \\
\text { Female cohorts }\end{array}$} & \multicolumn{2}{|c|}{$\mathrm{BMI}_{1} \geq 25 \mathrm{~kg} / \mathrm{m}^{2}$} & \multicolumn{2}{|c|}{$\mathrm{BMI}_{2} \geq 29 \mathrm{~kg} / \mathrm{m}^{2}$} & \multicolumn{2}{|c|}{$\mathrm{AHA} \geq 20 \mathrm{~g}$ ethanol/day } & \multicolumn{2}{|c|}{ Triglycerides $\geq 150 \mathrm{mg} / \mathrm{dl}$} \\
\hline & A & B & A & B & A & B & A & B \\
\hline BMI, kg/m² & $27 \pm 1$ & $27 \pm 1$ & $33 \pm 3$ & $32 \pm 2$ & $27 \pm 5$ & $26 \pm 4$ & $26 \pm 5$ & $27 \pm 5$ \\
\hline Age, years & $31 \pm 13$ & $41 \pm 11$ & $35 \pm 15$ & $36 \pm 11$ & $35 \pm 14$ & $42 \pm 11$ & $30 \pm 10$ & $41 \pm 6$ \\
\hline Glucose mg/dl & $85 \pm 9$ & $87 \pm 13$ & $90 \pm 16$ & $85 \pm 12$ & $88 \pm 15$ & $82 \pm 11$ & $88 \pm 11$ & $89 \pm 8$ \\
\hline Triglyceride mg/dl & $123 \pm 51$ & $166 \pm 114$ & $179 \pm 109$ & $145 \pm 61$ & $157 \pm 95$ & $124 \pm 45$ & $225 \pm 62$ & $257 \pm 12$ \\
\hline Cholesterol, C mg/dl & $189 \pm 46$ & $226 \pm 34$ & $228 \pm 31$ & $212 \pm 39$ & $236 \pm 36$ & $202 \pm 33$ & $235 \pm 44$ & $240 \pm 43$ \\
\hline LDL-C mg/dl & $139 \pm 5$ & $162 \pm 58$ & $154 \pm 53$ & $151 \pm 65$ & $160 \pm 61$ & $131 \pm 22$ & $164 \pm 44$ & $162 \pm 43$ \\
\hline Systol.RR mmHg & $124 \pm 24$ & $142 \pm 24$ & $142 \pm 20$ & $135 \pm 20$ & $137 \pm 22$ & $127 \pm 15$ & $133 \pm 20$ & $129 \pm 18$ \\
\hline Diast.RR mmHg & $82 \pm 14$ & $92 \pm 11$ & $96 \pm 14^{* *}$ & $91 \pm 16$ & $92 \pm 11$ & $88 \pm 11$ & $89 \pm 13$ & $88 \pm 9$ \\
\hline Oral Hormones & $29 \%$ of 17 & $29 \%$ of 14 & $19 \%$ of 16 & $30 \%$ of 10 & $29 \%$ of 21 & $21 \%$ of 14 & $31 \%$ of 26 & $17 \%$ of 12 \\
\hline *Smoking & $6 \%$ of 17 & $57 \%$ of $14^{*}$ & $6 \%$ of 16 & $40 \%$ of $10^{*}$ & $19 \%$ of 21 & $55 \%$ of $14^{*}$ & $22 \%$ of 26 & $58 \%$ of 12 \\
\hline AHA & $29 \%$ of 17 & $29 \%$ of 14 & $56 \%$ of 16 & $\mathrm{n}=1$ & elected & elected & $42 \%$ of 26 & $17 \%$ of 12 \\
\hline Urine Pathology & $29 \%$ of 17 & $50 \%$ of 14 & $31 \%$ of 16 & non & $52 \%$ of 21 & $50 \%$ of 14 & $38 \%$ of 26 & $25 \%$ of 12 \\
\hline
\end{tabular}

Diastolic hypertension did not change (A: $138 \pm 17 / 96 \pm 7$, 53 out of 163; B: $135 \pm 33 / 96 \pm 7$ mmHg, 35 out of 88 ). Alcohol- or triglyceride-related symptoms did not change in the overweight group $\left(\mathrm{BMI}_{1}\right)$ in view of age, cholesterol, blood glucose. Diastolic hypertension was found with obese women while only abstinent obese women had normal morning urines (B: $\left.\mathrm{BMI}_{2}\right)$. 


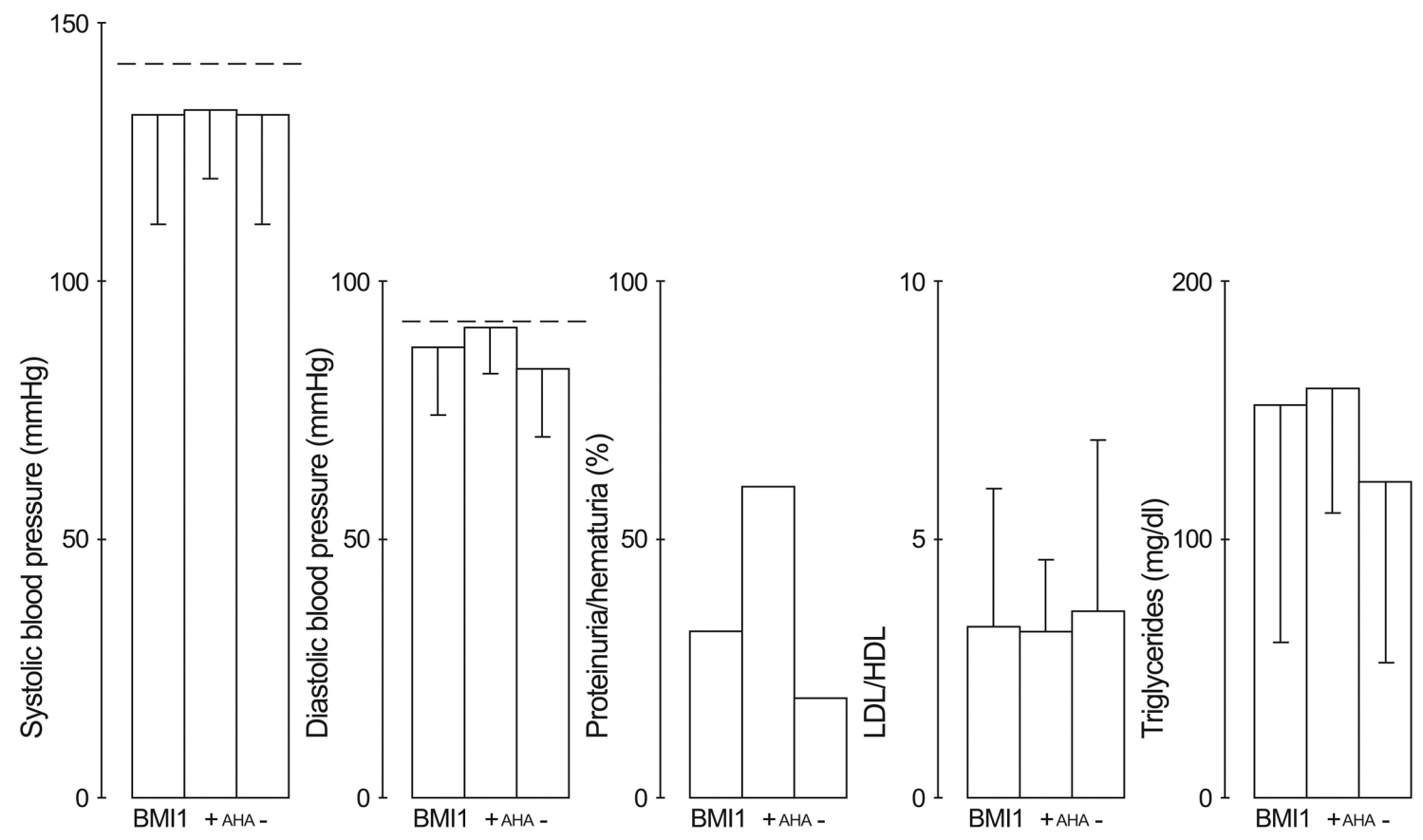

Figure 1. Women with overweight tended to critical lipid profiles and overlapping risk factors $\left(\mathrm{BMI}_{1}, 31\right.$ out of 248 (13\%)). Alcohol problems were often reported and paralleled with proteinuria and/or hematuria (+AHA: $38 \pm 19 \mathrm{~g}$ ethanol/day). Overlapping risk factors were classified and distinguished using risk-related subgroups (see Table 1). Values are means \pm 1 S.D.

had proteinuria and/or hematuria (Figure 2; Table 1, see AHA).

Indeed, alcohol problems were associated with rise of body weight $(p=0.011)$. Critical morning urines were associated with alcohol problems $(\mathrm{p}=0.044)$. Altogether, critical alcohol consumption declined renal endothelium (Table 1).

No additive effects were found testing urine pathology when women with alcohol problems smoked and/or had high LDL-cholesterol (Figure 2). No direct relationship was found between urine pathology and hypertension or between alcohol use and hypertension using multivariate analysis ( $p>0.1$ ). Thus, alcohol problems directly triggered urine pathology.

Daily alcohol consumption was then questioned again and was often confirmed when women showed hematuria (12 out of 35), proteinuria (7 out of 35) and/or urinary albumin (40 \pm 22 albumin $\mathrm{mg} / \mathrm{l}$, Figure 2 ). These women reported critical or heavy alcohol consumption in a reliable manner (10\% of 248: $40 \pm 40$ g ethanol/day; $4 \%$ of 248: $79 \pm 33 \mathrm{~g}$ ethanol/day). High variance of Gamma-GT confirmed the wide range of self-reported daily alcohol consumption (Figure 2).

The clear baseline message was that critical alcohol consumption significantly raised body weight and declined renal endothelium. Consenting women were trained and informed to monitor body weight and morning urines whereby standardized self-control documentations were offered to better prevent alcohol related urine pathology predicting small vessel disease.

\subsection{Subgroup 3. LDL-Related Mixed Hyperlipidemia}

\subsubsection{LDL-Related Hyperlipidemia Compared to Normolipidemia}

Next, women were selected on the basis of LDL-related hyperlipidemia and these women showed raised diastolic blood pressure and a higher proportion of urine pathology (Table 1). Hyperlipidemia and raised blood pressure overlapped with intolerance to glucose of women who tended to be overweight (Figure 3, Table 1). Normolipidemic participants showed normal weight and healthy baseline measures (Figure 3N, Table 1).

Indeed, women with LDL-related hyperlipidemia had significantly higher LDL-cholesterol $(p=0.002)$ and showed higher systolic, diastolic blood pressure ( $\mathrm{p}=$ $0.025, \mathrm{p}<0.001$ ) and a significantly higher proportion of urine pathology $(p=0.008)$ compared to normolipidemic women (Figure $3 \mathrm{C}$ versus $\mathrm{N}$ ).

A direct relationship was confirmed between LDLrelated hyperlipidemia and raised diastolic blood pressure ( $p=0.011$ ) using multivariate analysis of the study group. High total cholesterol and high LDL-cholesterol were correlated with aging ( $\mathrm{p} \leq 0.05)$. High LDL-cholesterol was further related with high triglycerides $(\mathrm{p}=$ 0.06). 


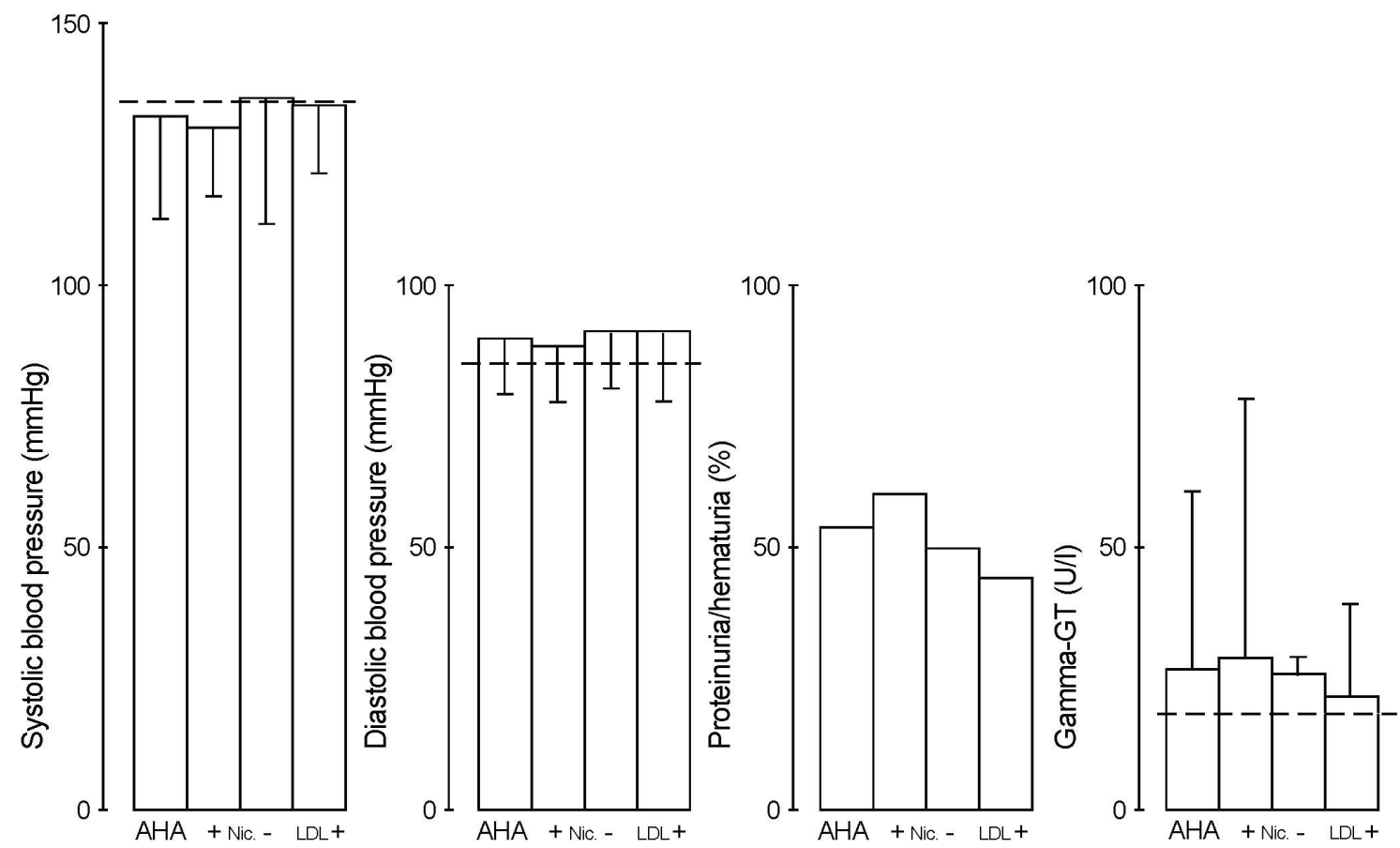

Figure 2. Women with alcohol problems were characterized and correlated with proteinuria/hematuria $(\mathrm{p}=0.044$, AHA: 35 out of 248). Alcohol problems were not aggravated by high LDL-cholesterol or smoking testing urine pathology (LDL+: $183 \pm 35 \mathrm{mg} / \mathrm{dl}, \mathrm{n}=9$; +NIC: $21 \pm 16$ cigarettes/day, $\mathrm{n}=13$ ). For details see text applied to subgroup 2 (Table 1). Values are means \pm 1 S.D.
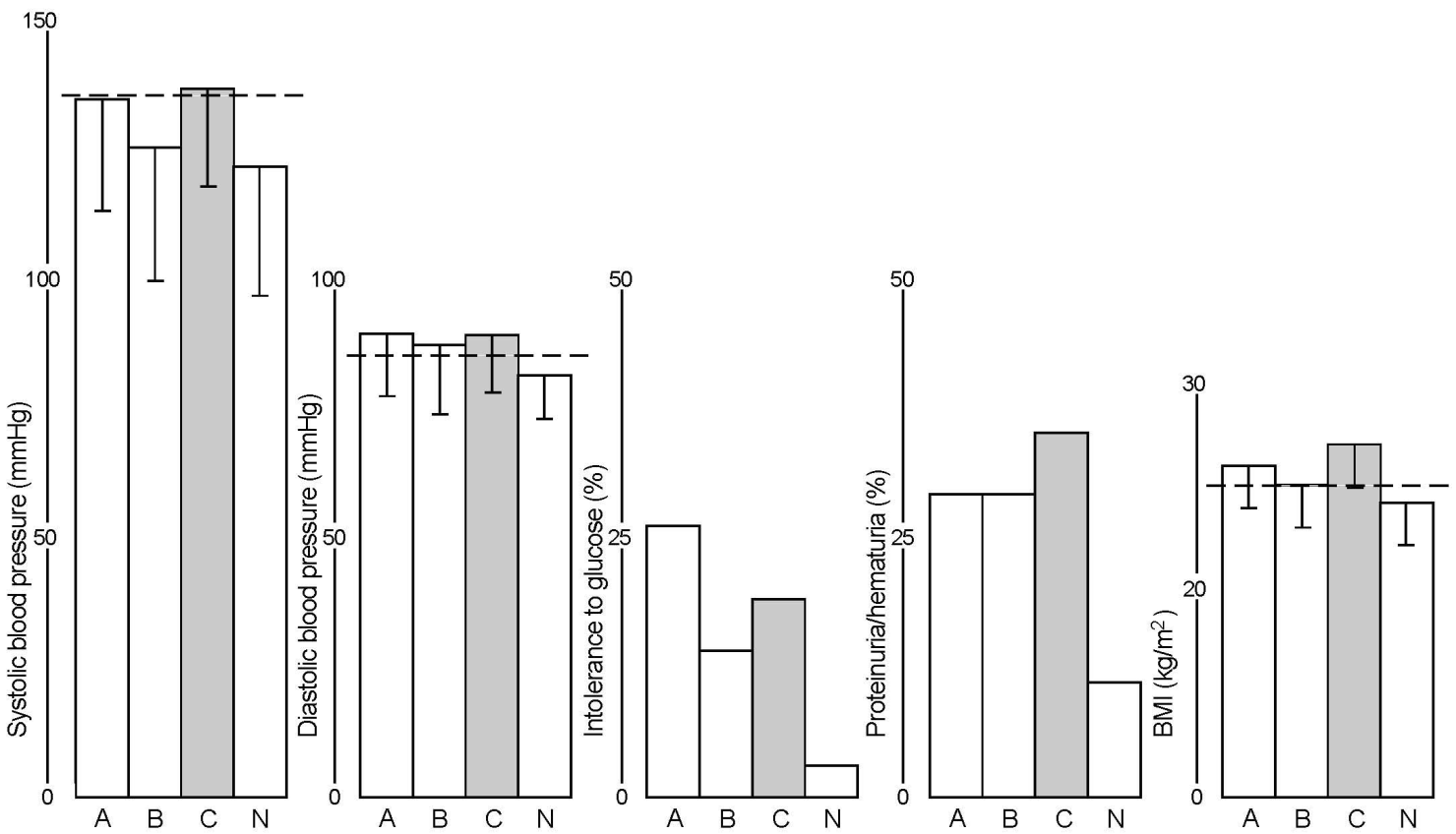

Figure 3. Women with critical lipid profiles showed higher blood pressure on the basis of high triglycerides (A: $240 \pm$ $65 \mathrm{mg} / \mathrm{dl}, 38$ out of 248) or LDL-related (mixed) hyperlipidemia (C: LDL + Trig, 26 out of 248) compared to normolipidemic women (N: 45 out of 248, p < 0.05). Women with high LDL-cholesterol tended to moderate rise of blood pressure (B: LDL-C: $180 \pm 30 \mathrm{mg} / \mathrm{dl}$, 28 out of 248). For details and percentage see text applied to subgroup 3 (Table 1). Additive effects of alcohol problems are shown in Table 3 . Values are means \pm 1 S.D.

The clear message was that LDL-related hyperlipidemia formed a multiple risk entity for diastolic hyperten- sion of women who often showed dysfunctional renal endothelium. LDL-related (mixed) hyperlipidemia was 
directly correlated with diastolic hypertension considering early lipid lowering and antihypertensive strategies. Medical monitoring of dietary strategies was combined with home control of blood pressure, body weight and morning urines of consenting women.

\subsubsection{Triglyceride-Related Problems and Alcohol Consumption}

Participants were then selected on the basis of high triglycerides as LDL-related hyperlipidemia overlapped and showed similar symptoms (Table 1).

Indeed, high triglycerides were also associated with hypertension ( $p=0.05$ ) and with intolerance to glucose $(p=0.021$, see Figure 3A vs N). High triglycerides were further related with rise of body weight and with urine pathology ( $p=0.07$, see Figure $3 \mathrm{~A}$ vs $\mathrm{N}$ ). Urine pathology was then related with critical fasting blood glucose $(p=0.07)$.

High triglycerides were directly correlated with intolerance to glucose and with critical diastolic blood pressure (Table 1). Quite surprisingly, intolerance to glucose was not directly correlated with critical fasting blood glucose probably because the participants were relatively young and inflammatory markers were initially excluded (Table 1, CRP: $0.6 \pm 0.2 \mathrm{mg} / \mathrm{dl}$ ).

Next, participants with high triglycerides were characterized on the basis of self-reported daily alcohol consumption (see AHA-Trig in Table 3). These women with alcohol-related hypertriglyceridemia showed critical fasting blood glucose in the presence of systolic and diastolic hypertension, urine pathology and relatively low HDLcholesterol (Table 3). Women with alcohol-related hypertriglyceridemia often reported critical (39 $\pm 17 \mathrm{~g}$ ethanol/day, $n=11$ ) or heavy alcohol use (64 \pm 9 g/day $\left.(\mathrm{n}=5), 29 \pm 4 \mathrm{~kg} / \mathrm{m}^{2}\right)$. Elevated Gamma-GT showed high variance (34 $\pm 19>30 \mathrm{U} / \mathrm{l})$ while plasma creatinine and inflammatory markers were in the normal range (Table 3; CRP $0.6 \pm 0.2 \mathrm{mg} / \mathrm{dl}$ ).

The good message was that alcohol-disowning women with high triglycerides showed healthy morning urines and only moderate rise of diastolic blood pressure (NATrig in Table 3). Women with nonalcoholic rise of triglycerides had functional renal endothelium, normal HDLcholesterol, normal fasting blood glucose and healthy hepatic and renal values (Gamma-GT: $12 \pm 5 \mathrm{U} / \mathrm{l}$, see NA-Trig of Table 3).

Table 3. Initial female lipid profiles were characterized with or without alcohol use. Alcohol-related mixed hyperlipidemia (LDL + Trig + AHA) versus nonalcohol (NA) hyperlipidemia showed lower HDL-cholesterol and hither LDL/HDL ( ${ }^{* *} \mathrm{p} \leq 0.05$, 3a vs 3b).

\begin{tabular}{|c|c|c|c|c|c|c|c|}
\hline Variables: & LDL + Trig + AHA (3a) & NA-LDL + Trig (3b) & AHA-Trig & NA-Trig & HDL-C & HDL-C $<60$ & $\mathrm{HDL} \geq 60$ \\
\hline Cases: & 16 of 26 & 10 of 26 & 16 of 38 & 22 of 38 & 96 of 248 & 46 of 96 & 50 of 96 \\
\hline HDL-C mg/dl & $48 \pm 12^{* * *}, p=0.01$ & $71 \pm 24$ & $48 \pm 13$ & $65 \pm 25$ & $63 \pm 18$ & $47 \pm 9$ & $76 \pm 14$ \\
\hline Age, years & $38 \pm 15$ & $41 \pm 17$ & $32 \pm 15$ & $36 \pm 13$ & $38 \pm 16$ & $35 \pm 15$ & $39 \pm 14$ \\
\hline Cholesterol, C mg/dl & $254 \pm 35$ & $266 \pm 49$ & $231 \pm 32$ & $240 \pm 43$ & $224 \pm 6$ & $247 \pm 49$ & $237 \pm 41$ \\
\hline LDL-C, mg/dl & $209 \pm 51$ & $174 \pm 17$ & $169 \pm 39$ & $163 \pm 47$ & $145 \pm 42$ & $151 \pm 39$ & $140 \pm 37$ \\
\hline Triglycerides & $243 \pm 95$ & $174 \pm 46$ & $247 \pm 75$ & $232 \pm 69$ & $137 \pm 86$ & $151 \pm 87$ & $117 \pm 60$ \\
\hline Fasting Glucose & $96 \pm 17,{ }^{*} \mathrm{p}=0.058$ & $83 \pm 5$ & $93 \pm 1$ & $84 \pm 6$ & $86 \pm 12$ & $90 \pm 11$ & $82 \pm 11$ \\
\hline LDL/HDL & $3.6 \pm 1,{ }^{* *} \mathrm{p}=0.001$ & $2.5 \pm 1.1$ & $3.1 \pm 1.1$ & $2.3 \pm 1.1$ & $2.4 \pm 1.1$ & $3.1 \pm 1.5$ & $1.9 \pm 0.6$ \\
\hline Alcohol use, AHA & 3a vs $3 b, p=0.0001$ & NA-elected & AHA-elected & NA-elected & $15 \%$ of 96 & $22 \%$ of 46 & $14 \%$ of 50 \\
\hline Smoking, NIC & 15 of 16 & NoNIc elected & 9 of $16,56 \%$ & 5 of $22,23 \%$ & $23 \%$ of 96 & $24 \%$ of 46 & $22 \%$ of 50 \\
\hline Systolic RR, mmHg & $135 \pm 18$ & $126 \pm 5$ & $146 \pm 25^{* *}$ & $133 \pm 5$ & $123 \pm 27$ & $133 \pm 24$ & $119 \pm 14$ \\
\hline Diastolic RR mmHg & $94 \pm 11,{ }^{* *} \mathrm{p}=0.004$ & $85 \pm 6$ & $96 \pm 11^{* *}$ & $86 \pm 8$ & $84 \pm 11$ & $86 \pm 14$ & $82 \pm 8$ \\
\hline BMI, kg/m² & $28 \pm 4$ & $24 \pm 2$ & $29 \pm 4$ & $27 \pm 5$ & $24 \pm 5$ & $25 \pm 5$ & $23 \pm 4$ \\
\hline Alb/Trig & $26 \pm 8$ & $55 \pm 28$ & $21 \pm 13$ & $25 \pm 8$ & $48 \pm 15$ & $36 \pm 13$ & $57 \pm 10$ \\
\hline PL-Creatinine mg/dl & $0.8 \pm 0.1$ & $0.9 \pm 0.1$ & $0.9 \pm 0.12$ & $0.7 \pm 0.1$ & $0.9 \pm 0.2$ & $0.7 \pm 0.2$ & $0.8 \pm 0.1$ \\
\hline PL-uric acid, mg/dl & $5.3 \pm 0.7$ & $4.6 \pm 1.2$ & $4.8 \pm 0.6$ & $4.8 \pm 1.1$ & $4.1 \pm 1$ & $4.6 \pm 12$ & $4.5 \pm 0.2$ \\
\hline CRP, mg/dl & $0.3 \pm 0.3$ & 0.30 .2 & $0.6 \pm 0.2$ & $0.4 \pm 0.3$ & $0.4 \pm 0.3$ & $0.3 \pm 0.2$ & $0.4 \pm 0.2$ \\
\hline Urine pathology & $44 \%$ of $16,{ }^{* *} \mathrm{p}=0.005$ & $\mathrm{n}=1$ & $44 \%$ of 16 & $14 \%$ of 96 & $14 \%$ of 96 & $22 \%$ of 46 & $14 \%$ of 50 \\
\hline
\end{tabular}

Alcohol-related hyperlipidemia was associated with raised blood pressure, urine pathology, lower HDL-C, raised fasting glucose. Significant rise of LDL/HDL and lowering of HDL-C were paralleled with lower albumin to triglyceride ratio (Alb/Trig). Nonalcohol hyperlipidemia showed normal values. Apoprotein A1 $(187 \pm 14 \mathrm{mg} / \mathrm{dl})$ was normal of hyperlipidemic representatives. For detail see text applied to subgroup No. 3. Values are means \pm 1 S.D. (3a vs $3 b,{ }^{* *} p \leq 0.05$, ${ }^{*} p$ $\leq 0.1)$. 
The negative message was provided with evidence. Indeed, high triglycerides raised diastolic blood pressure and daily alcohol consumption placed these women into a direct risk group for hypertension, raised body weight, urine pathology, critical fasting blood glucose and fatty liver disease. Thus, home monitoring of blood pressure had to be combined with medical testing of lipid profiles to prevent triglyceride-related hypertension considering lipid lowering and antihypertensive medical strategies.

\subsubsection{LDL-Related Hyperlipidemia and Alcohol Consumption}

Indeed, women with significantly higher LDL-cholesterol $(p=0.047)$ in the presence of mixed hyperlipidemia more often reported alcohol problems $(p=0.0001)$ and/or smoking $(p=0.009)$ compared to normolipidemic participants (Table 3). Women with LDL-related hyperlipidemia who reported alcohol use and/or smoking showed significantly raised diastolic blood pressure $(\mathrm{p}=$ $0.004)$, a higher proportion of dysfunctional endothelium $(\mathrm{p}=0.005)$ and of critical fasting blood glucose $(\mathrm{p}=$ 0.005) compared to hyperlipidemic women reporting healthy lifestyle (Table 3a vs b).

Benefit of healthy lifestyle was shown with hyperlipidemic controls reporting healthy lifestyle as alcoholdisowning women showed functional renal endothelium and normal fasting blood glucose (Table $3 \mathbf{b}$ ).

Altogether, evidence was provided that women with LDL-related (mixed) hyperlipidemia who reported critical alcohol consumption were at direct risk for adverse symptoms consisting of diastolic hypertension, dysfunction of renal endothelium and critical fasting blood glucose. Thus, alcohol-related mixed hyperlipidemia formed a direct risk class for hepatic and renal problems implicating combined medical strategies and cessation of smoking.

The evident negative message was that critical alcohol consumption placed hyperlipidemic women into a direct risk class for hypertension, small vessel disease and critical fasting blood glucose. These women had to cede drinking and smoking. Home monitoring of blood pressure, body weight and morning urines was skilled to initiate low fat diets combined with healthy nonalcohol liquids.

\subsubsection{Lowering of Female HDL-Cholesterol}

Furthermore, women with alcohol-related mixed hyperlipidemia showed significantly lower HDL-cholesterol $(\mathrm{p}=0.01)$ and significantly higher LDL/HDL $(\mathrm{p}=$ 0.001) compared to hyperlipidemic participants reporting healthy lifestyle (Table 3). Women with high triglycerides reporting alcohol problems also showed rise of LDL/HDL and lowering of HDL-cholesterol (Table 3).

Next, critical cholesterol ratio (LDL/HDL) was paral- leled with low ratio of albumin to triglycerides, critical fasting blood glucose and rise of diastolic blood pressure (Table 3). Likewise, selection with low ratio of serum albumin to triglycerides (Alb/Trig $\leq 40: 27 \pm 5$ ) led to participants with low HDL-cholesterol (HDL-C: $53 \pm 2$ $\mathrm{mg} / \mathrm{dl}$ ) and half of these women reported critical alcohol consumption (48 $\pm 12 \mathrm{~g}$ ethanol/day, aged $34 \pm 8$ years, $\mathrm{n}$ $=20$ ).

Healthy levels of HDL-cholesterol were found here with smoking women. In fact, multivariate analysis of the study group did not find a direct effect of smoking probably because these participants were relatively young. There was a moderate (indirect) relationship between smoking and critical body weight $(\mathrm{p}=0.1)$ indicating that some women might smoke to reduce body weight. Nevertheless, these young smoking women had to perceive that smoking raised body weight in the presence of daily alcohol consumption ( $\mathrm{p}=0.07,17 \pm 9$ cigarettes per day, 20 out of 60 , aged $37 \pm 15$ years).

The motivating message was that women with LDLrelated hyperlipidemia who disowned daily alcohol consumption showed healthy levels of HDL-cholesterol, normal Alb/Trig and healthy morning urines (Table 3). Likewise, healthy HDL-cholesterol was found with normolipidemic women who had normal Alb/Trig and normal fasting blood glucose (Tables 1 and 3).

The negative message was provided with evidence showing that alcohol-related mixed hyperlipidemia lowered HDL-cholesterol and increased LDL/HDL. Medical counseling strongly recommended improved quality of food and lifestyle as women at risk had to replace critical alcohol consumption by healthy liquids without alcohol. An impaired HDL-related defense system needed medical monitoring and appropriate therapeutical strategies.

\section{DISCUSSION}

The present study found that women with LDL-related (mixed) hyperlipidemia were at direct risk for diastolic hypertension. Alcohol problems and/or smoking declined renal endothelium as shown here with apparently healthy primary care women who initially attended a medicine practice.

Indeed, women with LDL-related (mixed) hyperlipidemia had significantly higher blood pressure and more often reported alcohol problems and smoking showing then rise of body weight and a higher proportion of urine pathology compared to controls. Hematuria and/or proteinuria of the participants were specifically related with self-reported alcohol problems. Healthy morning urines were found with hyperlipidemic women reporting healthy lifestyle and with normolipidemic participants (see subgroup 3). High triglycerides were associated with hypertension and intolerance to glucose whereby critical alco- 
hol consumption aggravated hypertension and declined renal endothelium comparing hyperlipidemic women with versus without alcohol problems. Thus, high triglycerides were related with hypertension whereby critical alcohol consumption triggered dysfunction of renal endothelium. Urine pathology showed an indirect relationship with rise of fasting blood glucose indicating a role of alcohol-related small vessel disease.

Medical examinations at baseline were subsequently combined with self testing of blood pressure of consenting women who wanted to neutralize midlife risk factors for kidney disorders, stroke and small vessel disease [6, $14,21]$. Consenting women were informed here that albuminuria predicts cardiovascular disorders of elderly persons indicating that aging further impaired regeneration of impaired endothelium [9,14,41,57].

Primarily healthy women at risk often wanted here to reduce body weight while these women had to perceive that critical alcohol consumption and smoking raised body weight and declined renal endothelium implicating to cede drinking and smoking. Medical counseling recommended higher quality of food without adverse components to be combined with healthy nonalcohol liquids to repair dysfunction of renal endothelium, to improve the defense potency of HDL-particles. Hyperlipidemic and/or obese women had to perceive a direct risk for diastolic hypertension to be prevented as well. Critical daily alcohol consumption raised fasting blood glucose and risk for fatty liver disease of hyperlipidemic women so that change of adverse habits was initiated as shown with representative cases [53-55].

Telemedical counseling helped to overcome ambivalent problems [53-55]. Combined interventional strategies were offered when women at risk showed poor selfcontrol [www.fida-aha.com, 21,58]. There was a beneficial outcome of healthy lifestyle as alcohol-disowning hyperlipidemic women had functional renal endothelium, healthy HDL-related system and healthy liver values as shown before with representative cases [53-55]. The renal endothelium even of abstinent former alcohol abusers can recover in some degree when they obtain healthy supplements with low fat milk products as shown before $[5,26,53]$. Obese women tended to hypertension here and before whereby specifically abstinent obese women showed healthy morning urines [26,54]. Elderly smoking women recover from hematuria throughout five years of selfreported low fat diets when heavy smoking was at least reduced (www.fidabus.com) [26,55]. Healthy food was adapted for medical need to antagonize early small vessel disease with healthy diets and change of adverse lifestyle behavior [26,54-56].

Indeed, the most injurious female outcome was found here with lowering of HDL-cholesterol of hyperlipidemic women who reported critical alcohol consumption.
These women with alcohol-related hyperlipidemia had significantly lower HDL-cholesterol and higher LDL/ HDL compared to alcohol-disowning women with LDLrelated hyperlipidemia. Furthermore, women with alcohol-related mixed hyperlipidemia often showed critical fasting blood glucose. Alcohol-related mixed hyperlipidemia triggered here dyslipidemia and predicted critical fasting blood glucose on the basis of elevated LDL/HDL $(\geq 3.0)$ and relatively low HDL-cholesterol $(<60 \mathrm{mg} / \mathrm{dl})$. Low ratio of serum albumin to triglycerides (Alb/Trig $\leq 40$ ) was paralleled with critical fasting blood glucose indicating disturbed regeneration of pancreas beta-cells. The good message was that normolipidemic women had normal biomarkers indicating a robust HDL-related defense system in the presence of moderate lifestyle problems. Overall, declined HDL-related defense system was found here with women selected with elevated LDL/ HDL and low Alb/Trig and these women tended to critical fasting blood glucose.

Baseline science shows that human HDL-particles carry ether phospholipids, chemically 1-alkyl-2-(shortchain)acyl-sn-glycero-phosphocholines (LA-paf). Enzymatic betaoxidation shortens fatty acids esterified in position 2 of glycerophospholipids in an unfavorable manner [1]. Medical science further shows that triglyceride-enriched HDL-particles are discharged by lipases and/or phospholipases [59]. Phospholipases/acetylhydrolases are expressed on outer membranes of activated endothelium explaining at least in part that women with low HDL-cholesterol were at risk for diastolic hypertension as well $[6,21]$. These dyslipidemic women needed strict medical strategies to neutralize indicated risk factors considering lipid lowering and antihypertensive pharmacotherapy whereby healthy dietary habits and behavior can repair dysfunction of HDL-particles in general.

Classical European reports propose some benefit of low alcohol consumption on the basis of HDL-related lipoproteins testing population-based study groups [60]. These geographical alcohol reports are not contradictory to valid German guidelines opposing at least risky, critical, heavy alcohol consumption [40]. It is known that heavy alcohol consumption outside of healthy meals triggers hepatic disorders with combined systolic and diastolic hypertension whereby aging aggravates hypertension in general [reviewed in 41]. Renal or inflammatory disorders were excluded here at baseline and CRP-levels were normal as well. Septic mediators such as the acetylated phosphocholine (PAF-Acether) trigger alcoholic steatohepatitis while hepatic disorders were initially excluded [reviewed in 31]. As known, alcohol abusers show high plasmatic levels of transformed phospholipids indicating high oxidative stress of alcohol using persons $[1,50,61]$.

Human cells are protected by free serum albumin 
against alcohol-related ether phospholipids in general [1-3,22-26]. However, endogenously transformed serum albumin emigrates as shown here with urinary albumin [4-6,21,31]. Albumin carries lyso paf from inside the vessels out whereby lyos paf is formed by phospholipases, acetylhydrolases of lipoproteins and/or outer cell membranes [20,23]. Significant increase of upregulatory lyso paf is shown because lyso paf significantly increased in the subendothelium and/or in cerebrospinal fluids of persons suffering of disturbed endothelium barriers and/or of psychotic disorders with and without dementia [3-6,56].

The major limitation of this study was that transformed phospholipids were not measured in the morning urines. Another limitation was that heavy drinking and smoking were not compared with moderate lifestyle problems and that self-reported adverse habits can be undervalued. The advantage of this report was that a complete set of initial baseline measures was scored and explored here in the same form since 1990.

Smoking women often reported here critical family history on the basis of high cholesterol, hypertension, type 2 diabetes mellitus and/or age-related cardiovascular disorders (19\% of 248). Smoking women had to perceive that smoking and aging aggravate unhealthy effects of cholesterol to implement combined medical strategies in accordance with the guidelines $[6,37,42,62]$. Other reports show that transformed phospholipids can interact with nuclear peroxisome proliferator-activated receptors (PPARs) whereby nuclear receptors disturb lipid turnover in general [63, reviewed in 30].

Additive effects of alcohol problems and hyperlipidemia are supported by experimental science as lipoproteins carry alcohol-related ether phospholipids and interact with human endothelium on the basis of specific alkyl receptors such as lyso paf receptors which are not directly related with LDL-receptors [1-4] Recent reports show vulnerable gene variants which can encode lipoprotein-associated lipases of Asian persons suffering of hypertension [64]. Some mutants of phospholipases/acetylhydrolases predict stroke of Japanese persons while elderly Caucasians with late arterial disorders fail significant correlations testing lipoprotein-associated PLA2G7-gene variants $[65,66]$. Relevant mutants of hepatic lipases are correlated with nonalcoholic steatohepatitis of US-persons who are sensitive to obesity [67]. The geographical differences of phenotypes might lead to rare genotypes testing lipases/phospholipases by preference of younger healthy persons suffering of unclear hypertension [68].

Phenotype ranking provided here progress to promote a higher quality of food and lifestyle as benefit is shown with abstinent obese women and/or with aging women who reduced smoking having then normal morning urines [53-56]. Warning messages were provided here with evi- dence as critical alcohol consumption declined renal endothelium and aggravated hypertension in the presence of LDL-related (mixed) hyperlipidemia.

Altogether, hyperlipidemic women had to perceive and confirm a higher risk showing that critical lifestyle behavior placed them into a direct risk group for hypertension, dysfunctional renal endothelium, lowering of HDL-cholesterol and critical fasting blood glucose. Combined medical strategies and/or healthy lifestyle behavior reached here some benefit as alcohol-disowning women with high triglycerides had functional endothelium and normal HDL-cholesterol.

\section{CONCLUSION}

Primarily healthy women with LDL-related (mixed) hyperlipidemia were at direct risk for diastolic hypertension. Critical alcohol consumption and smoking placed hyperlipidemic women into an even higher risk group for hypertension, dysfunctional renal endothelium, rise of body weight, lowering of HDL-cholesterol and rise of fasting blood glucose. The multiple risk entity implicated medical strategies replacing adverse alcohol consumption by healthy liquids without alcohol combined with medical monitoring of metabolic risk factors.

\section{ACKNOWLEDGEMENTS}

Author has no conflicts of interest.

\section{REFERENCES}

[1] Korth, R., Zimmermann, K. and Richter, W. (1994) Lipoprotein-associated paf (LA-paf) was found in washed human platelets and monocyte-macrophage-like U937 cells. Chemistry Physics of Lipids, 70, 109-119. http://dx.doi.org/10.1016/0009-3084(94)90079-5

[2] Korth, R.M., Hirafuji, M., Benveniste, J. and RussoMarie, F. (1995) Human umbilical vein endothelial cells: Specific binding of platelet-activating factor and cytosolic calcium flux. Biochemical Pharmacology, 49, 1793-1799. http://dx.doi.org/10.1016/0006-2952(95)00025-U

[3] Korth, R.M. (1997) Specific binding sites for 1-O-alkylsn-glyceryl-3-phosphorylcholine on intact human blood neutrophils. International Archives of Allergy and Immunology, 113, 460-464.

http://dx.doi.org/10.1159/000237623

[4] Korth, R.M. (2000) Comparison of phosphocholines in human plasma and cerebrospinal fluid (CSF). Faseb Journal, 14, A72.

[5] Korth, R.M. (2002) AHA-syndromes. Chemistry and Physics of Lipids, 118, 96-97.

[6] Korth, R.M. (2006) Gender obesity, alcohol use, hyperlipidemia, hypertension and declined renal endothelial barriers. Journal Men's Health and Gender JMHG, 3, 279-289. http://dx.doi.org/10.1016/j.jmhg.2005.08.006 
[7] Solbu, M., Kronborg, J., Erikson, B.O., Jenssen, T.G. and Toft, I, (2008) Cardiovascular risk-factors predict progression of urinary albumin-excretion in a general, nondiabetic population. A gender-specific follow-up study. Atherosclerosis, 201, 398-406. http://dx.doi.org/10.1016/j.atherosclerosis.2008.02.027

[8] Vasan, R.S. (2005) Relative importance of borderline and elevated levels of coronary heart disease risk factors. Annals Internal Medicine, 142, 393-402.

http://dx.doi.org/10.7326/0003-4819-142-6-200503150-0 $\underline{0005}$

[9] Barzilay, J.J., Peterson, D., Cushman, M., Heckbert, S.R., Cao, J.J., Blaum, C., Tracy, R.P., Klein, R. and Herrington, D.M. (2004) The relationship of cardiovascular risk factors to microalbuminuria in older adults with or without diabetes mellitus or hypertension. The Cardiovascular Health Study. American Kidney Disease, 44, 25-34. http://dx.doi.org/10.1053/j.ajkd.2004.03.022

[10] Maas, R., Schulze, F., Baumert, J., Löwel, H., Hamraz, K., Schwedhelm, E., Koenig and W., Böger, R.H. (2007) Asymmetric dimethylarginine, smoking, and risk of coronary heart disease in apparently healthy men: Prospective analysis from the population-based Monitoring of Trends and Determinants in Cardiovascular disease/Kooperative Gesundheitsforschung in der Region Augsburg Study and Experimental Data. Clinical Chemistry, 53, 693-701. http://dx.doi.org/10.1373/clinchem.2006.081893

[11] Fröhlich, M., Sund, M., Lowel, H., Imhof, A., Hoffmeister, A. and Koenig. W. (2003) Independent associations of various smoking characteristics with markers of systemic inflammation in men. Results from a representative sample of the general population (MONICA) Augsburg Survey 1994/1995). European Heart Journal, 24, 1365-1372. http://dx.doi.org/10.1016/S0195-668X(03)00260-4

[12] Patja, K., Jousilahti, P., Hu, G., Valle, T., Quiao, Q. and Tuomilehto, J. (2005) Effects of smoking, obesity and physical activity on the risk of type 2 diabetes in middleaged Finnish men and women. Journal Internal Medicine, 258, 356-362. http://dx.doi.org/10.1111/j.1365-2796.2005.01545.x

[13] Su, J., Georgiades, A., Wu, R., Thulin, T., de Faire, U., Frostegard, J. (2006) Antibodies of IgM subclass to phosphorylcholine and oxidized LDL are protective factors for atherosclerosis in patients with hypertension. Atherosclerosis, 188, 160-166. http://dx.doi.org/10.1016/j.atherosclerosis.2005.10.017

[14] Kristjansson, K., Ljungmann, S., Bengtsson, C., Björkel, C. and Sigurdsson, J.A (2001) Microproteinuria and longterm prognosis with respect to renal function and survival in normotensive and hypertensive women. Scandinavian Journal Urology Nephrology, 35, 63-70. http://dx.doi.org/10.1080/00365590151030868

[15] Wu, R., Lemne, C., De Faire, U. and Frostegard, J. (1997) Antibodies to platelet-activating factor are associated with borderline hypertension, early atherosclerosis and the metabolic syndrome. Journal Internal Medicine, 246, 389-397. http://dx.doi.org/10.1046/j.1365-2796.1999.00570.x

[16] Wohlin, M., Sundström, J., Ärnlöv, J., Andrén, B., Zethelius, B. and Lind L. (2003) Impaired insulin sensitivity is an independent predictor of common carotid intima-media thickness in a population sample of elderly men. Atherosclerosis, 170, 181-183. http://dx.doi.org/10.1016/S0021-9150(03)00283-1

[17] Erkkilä, A.T., Närvänen, O., Lehto, S., Uusitupa, M.I.J. and Ylä-Herttiala, S. (2005) Antibodies against oxidized LDL and cardiolipin and mortality in patients with coronary heart disease. Atherosclerosis, 183, 157-162. http://dx.doi.org/10.1016/j.atherosclerosis.2005.02.026

[18] Fujimura Y, Hwang PM, Trout H, Kozloff L, Imaizumi M, Innis RB and Fujita M. (2008) Increased peripheral benzodiazepine receptors in arterial plaques of patients with arteriosclerosis: An autoradiographic study with $\left[{ }^{3} \mathrm{H}\right]$ PK11195. Atherosclerosis, 201, 108-111. http://dx.doi.org/10.1016/j.atherosclerosis.2008.02.032

[19] Korth, R., Hirafuji, M., Lalau Keraly, C., Delautier, D., Bidault, J. and Benveniste, J. (1989) Interaction of the paf antagonist WEB 2086 and its hetrazepine analogues with human platelets and endothelial cells. British Journal Pharmacology, 98, 653-661. http://dx.doi.org/10.1111/j.1476-5381.1989.tb12640.x

[20] Korth, R. and Middeke, M. (1991) Long time incubation of monocytic U 937 cells with LDL increase specific PAF-acether binding and the cellular acetylhydrolase activity. Chemistry Physics of Lipids, 59, 207-213. http://dx.doi.org/10.1016/0009-3084(91)90020-C

[21] Korth, R.M. (2012) Two male study groups with adiposity and hypertriglyceridemia were at risk for hypertension and alcohol use decline renal endothelium. Health, 4, 1413-1419.

[22] Korth, R. and Benveniste J. (1988) BN 52021 displaces [3H]paf-acether from, and inhibits its binding to intact human platelets. European Journal Pharmacology, 142, 331-341. http://dx.doi.org/10.1016/0014-2999(87)90071-9

[23] Korth, R., Bidault, J., Palmatier, R., Benveniste, J. and Ninio, E. (1993) Human platelets release a paf-acether: Acetylhydrolase similar to that in plasma. Lipids, 28, 193-199. http://dx.doi.org/10.1007/BF02536639

[24] Frei, B., Stocker, R. and Ames, B.N. (1988) Antioxidant defenses and lipid perioxidation in human plasma. Proceedings. National Academy of Science, 85, 9748-9752. http://dx.doi.org/10.1073/pnas.85.24.9748

[25] Korth, R.M. (1997) VLDL and PAF binding to human endothelial cells. Chemistry and Physics of Lipids, 88, 134.

[26] Korth, R.M. (2007) Novel compositions against alkyl-acyl-GPC, the derivatives and products thereof. Publ. No. WO 2007/073727.

[27] Faure, P., Troncy, L., Lecomte, M., Wiernsperger, N. Lagarde, M., Ruggerio, D. and Halimi, S., (2005) Albumin antioxidant capacity is modified by methylglyoxal. Diabetes \& Metabolism, 31, 169-177. http://dx.doi.org/10.1016/S1262-3636(07)70183-0

[28] Uribarri, J., Woodruff, S., Goodman, S., Cai, W., Chen, X., Pyzik, R., Yong, A., Striker, G.E. and Vlassara, H. (2010) Advance glycation end products in Foods and a practical Guide to their reduction in the diet. Journal American Dietary Association, 110, 911-916. http://dx.doi.org/10.1016/j.jada.2010.03.018 
[29] Chen, H.C. (2001) Molecular Mechanisms of sterol absorption. Journal Nutrition, 131, 2603-2605.

[30] Silva, I.T., Mello, A.P.Q. and Damasceno, N.R.T. (2011) Antioxidant and inflammatory aspects of lipoproteinsassociated phospholipases A2 (LP-PLA2): A review. Lipids Health Disease, 10, 170.

[31] Korth, R.M. (2001) Ether-linked phospholipids and hyperlipidemia. Recent Res. Devel. Lipids, S.G. Pandalai Publisher, Transworld Research Network, Trivandrum, 61-70.

[32] Berenson, G.S., Srinivasan, S.R., Bao, W., Newmann, W.P., Tracy, R.E. and Wattigney, W.A. (1998) Association between multiple cardiovascular risk factors and atherosclerosis in children and young adults. New England Journal Medicine, 338, 1650-1656. http://dx.doi.org/10.1056/NEJM199806043382302

[33] Volek, J.S., Fernandez, M.L., Feinman, R.D. and Phinney, S.D. (2008) Dietary carbohydrate restricition induces a unique metabolic state positively affecting atherogenic dyslipidemia, fatty acid partioning, and metabolic syndrome. Progress in Lipid Research, 47, 307-318. http://dx.doi.org/10.1016/j.plipres.2008.02.003

[34] Bartz, R., Li, W.H., Venable, B.H., Zehmer, J.K., Welti, M.R., Aderson, R.G.W., Liu, P. and Chapman, K.D. (2007) Lipidomics reveals that adiposome store ether lipids and mediate phospholipid traffic. Journal Lipid Research, 48, 837-847. http://dx.doi.org/10.1194/jlr.M600413-JLR200

[35] Sacks, F.M., Svetkey, L.P., Vollmer, W.M., Appel, L.J., Bray, G.A., Harsha, D., Obarzanek, E., Conlin, P.R., Miller, E.R., Simons-Morton, D.G., Karanja, N. and Lin, P.H.L.N. (2001) DASH-Sodium Collaboration Research Group. Effects on blood pressure of reduced dietary sodium and the dietary approaches to stop hypertension (DASH) diet. New England Journal Medicine, 344, 3-10. http://dx.doi.org/10.1056/NEJM200101043440101

[36] Querzfurth, H.W. (2010) Review article. Mechanism of disease Alzheimer' disease. New England Journal of Medicine, 362, 329-344. http://dx.doi.org/10.1056/NEJMra0909142

[37] Catapano, A.L., Reine, Z., De Backer, G., et al. (2011) ECS/EAS guidelines for the management of dyslipidemias. The task force for the management of dyslipidemias of the European Society of Cardiology (ESC) and the European Atherosclerosis Society (EAS). S Humphries Publisher, Atherosclerosis, Suppl. 21751.

[38] Ambrosio, G., Oriente, A., Napoli, C., Palumbo, G., Chiariello, P., Marone, G., Condorelli, M., Chiariello, M. and Triggiani, M. (1994) Oxygen radicals inhibit human plasma acetylhydrolase, the enzyme that catabolized plateletactivating factor. Journal of Clinical Investigation, 93, 2408-2416. http://dx.doi.org/10.1172/JCI117248

[39] Tokumura, A., Sumida, T., Toujima, M., Kogure, K., Fukuzawa, K., Takahashi, Y. and Yamamoto, S. (2000) Structural identification of phosphatidylcholines having an oxidatively shortened linoleate residue generated through its oxygenation with soybean or rabbit reticulocyte lipoxygenase. Journal of Lipid Research, 41, 953-962.

[40] Kraus, A.R. (2008) Alkoholkonsum, alkoholbezogene probleme und trends. Ergebnisse des epidemiologischen suchtsurvey 2003. Robert Koch Institut, Gesundheitsberichterstattung des Bundes 2008, Heft 40.

[41] Aronow, W.S., Fleg, J.L. and Peine, C.J. (2011) ACCF/AHA 2011 expert consensus document on hypertension in the elderly. Journal of the American College of Cardiology, 57, 2037-2114.

[42] Amareno, P., Goldstein, L.B. and Szarek, M. (2007) Effect of intense low-density lipoprotein cholesterol reduction in patients with stroke or transient ischemic attack: The stroke prevention by agressive reduction in cholesterol levels (SPARCL) trial. Stroke, 38, 3198-3204. http://dx.doi.org/10.1161/STROKEAHA.107.493106

[43] Kathiresan, S., Melander, O., Guiduccis, C., Surti, A., Burth, N.P., Rieder, M.J., Cooper, G.M., Roos, C., et al. (2008) Six new loci associated with blood low-density lipoprotein cholesterol, high density lipoprotein cholesterol, highdensity lipoprotein cholesterol or triglycerides in humans. Nature Genetic, 40, 189-197.

http://dx.doi.org/10.1038/ng.75

[44] Taylor, A.J., Villines, T.C., Stanek, E.J., Devine, D.P., Griffen, L., Miller, M., Weissmann, N.J. and Turco, M. (2009) Extended-release niacin or ezetimibe and carotid intimamedia thickness. New England Journal of Medicine, 361, 2113-2122. http://dx.doi.org/10.1056/NEJMoa0907569

[45] Winkler, K., Abletshauser, C., Friedrich, I., Hoffmann, M.M., Wieland, H. and Marz, W. (2004) Fluvastatin slow-release lowers platelet-activating factor acetylhydrolase activity: A placebo-controlled trial in patients with type 2 diabetes. Journal of Clinical Endocrinology \& Metabolism, 89, 1153-1159. http://dx.doi.org/10.1210/jc.2003-031494

[46] Vergeer, M., Holleboom, A.G., Kastelein, J.J.P. and Kuivenhoven, J.A. (2010) The HDL hypothesis: Does highdensity lipoprotein protect from atherosclerosis. Journal of Lipid Research, 51, 2058-2073. http://dx.doi.org/10.1194/jlr.R001610

[47] The Aim-High-Investigators (2011) Niacin in patients with low HDL cholesterol levels receiving intensive statin therapy. New England Journal of Medicine, 365, 2255-2267. http://dx.doi.org/10.1056/NEJMoa1107579

[48] Kheras, A.V., Cuchel, M., de la Llera-Moya, M., Rodrigues, A., Burke, M.F., Jafri, K., French, B.C., Phillips, J.A., Mucksavage, M.L., Wilensky, R.L., Mohler, E.R., Rothblatt, G.H. and Rader, D.J. (2011) Cholesterol efflux capacity, high density lipoprotein function and atherosclerosis. New England Journal of Medicine, 364, 127-135. http://dx.doi.org/10.1056/NEJMoa1001689

[49] Parat, G, Stergiou, G.S., Asmar, R., Bilo, G., de Leeuw, P., Imai, Y., Kario, K., Lurbe, E., Manolis, A., Mengden, T., O’Brien, E., Ohkubo, T., Padfield, P., Palatini, P., Pickering, T.G., Redon, J., Revera, M., Ruilope, L.M., Shennan, A., Staessen, J.A., Tisler, A., Waeber, B., Zanchetti, Mancia, G. and on behalf of ESH Working Group on Blood pressure Monitoring (2010) European society of hypertension practice guidelines for home blood pressure monitoring. Journal of Human Hypertension, 24, 779-785.

[50] Nofer, J.R., Kehrel, B., Fobker, M., Levkau, B., Assmann, G. and von Eckardstein, A. (2002) HDL and arteriosclerosis: Beyond reverse cholesterol transport. Atherosclero- 
sis, 161, 1-16. http://dx.doi.org/10.1016/S0021-9150(01)00651-7

[51] Fournier, N., Myara, I., Atger, V. and Moatti, N. (1995) Reactivity of lecithin-cholesterol acyltransferase (LCAT) towards glycated high-density lipoproteins (HDL). Clinica Chimica Acta, 234, 47-61. http://dx.doi.org/10.1016/0009-8981(94)05975-X

[52] Hoang, A., Tefft, C., Duffy, S.J., Formosa, M., Henstridge, D.C., Kingwell, B.A. and Sviridov, D. (2008) ABCA1 expression in humans is associated with physical activity and alcohol consumption. Atherosclerosis, 197, 197-203. http://dx.doi.org/10.1016/j.atherosclerosis.2007.03.017

[53] Korth, R.M. (2005) Gender dyslipidemia and ether phospholipids. FASEB Journal, 19, A109.

[54] Korth, R.M. (2007) Obesity mediated hypertension while alcohol use declined renal endothelial barriers of women. FASEB Journal, 21, A1361.

[55] Korth, R.M. (2007) Smoking, borderline LDL levels and renal small vessel disease of women with overweight. Atherosclerosis Supplements, 8, 32-33. http://dx.doi.org/10.1016/S1567-5688(07)71069-3

[56] Korth, R. (2002) Treatment of lyso paf-mediated disorders with lyso paf or paf antagonists and procedure for determining their efficacy. United States Patent Application Publication Pub. No. 2002/0127287 A1.

[57] Hillege, H.L., Fidler, V., Diercks, G.F.H., van Gilst, W.H., de Zeeuw, D., van Veldhuisen, D.J., Gans, R.O.B., Janssen, W.M.T., Grobbee, D.E., de Jong, P.E. and Prevention of Renal and Vascular End Stage Disease (Prevend) study group (2002) Urinary albumin excretion predicts cardiovascular and noncardiovascular mortality in general population. Circulation, 106, 17777-17782. http://dx.doi.org/10.1161/01.CIR.0000031732.78052.81

[58] Bosworth, H.B., Olsen, M.K., McCant, F., Harrelsons, M., Gentry, P., Rose, C., Goldstein, M.K., Hoffman, B.B., Powers, B. and Oddone, E.Z. (2007) Hypertension Intervention Nurse Telemedicine Study (HINTS): Testing a multifactoral tailored behavioral/edcuational and a medication management intervention for blood pressure control. American Heart Journal, 153, 918-914. http://dx.doi.org/10.1016/j.ahj.2007.03.004

[59] Lamarche, B., Uffelmann, K.D., Carpentier, A., Cohn, J.S., Steiner, G., Barrett, P.H. and Lewis, G.F. (1999) Triglyceride enrichement of HDL enhances in vivo metabolic clearance of HDL apo A1 in healthy men. Journal of Clinical Investigation, 103, 1191-1199. http://dx.doi.org/10.1172/JCI5286

[60] Marques-Vidal, P., Montaye, M., Haas, B., Bingham, A., Evans, A., Juhan-Vague, I., Ferrières, J., Luc, G., Amouyel, P., Arveiler, D., Yarnell, J., Ruidavets, B.J., Scarabin, P.Y. and Ducimetrière, P. (2001) Relationship between alcoholic beverages and cardiovascular risk factor levels in middle-aged men, the PRIME study. Atherosclerosis, 157, 431-440. http://dx.doi.org/10.1016/S0021-9150(00)00734-6

[61] Adachi, J., Matsushita, S., Yoshioka, N., Funae, R., Fujita, T., Higuchi, S. and Ueno, Y. (2004) Plasma phosphati- dylcholine hydroperoxide as a new marker of oxidative stress in alcoholic patients. Journal of Lipid Research, 45, 967-971. http://dx.doi.org/10.1194/jlr.M400008-JLR200

[62] Hildenbrand, M.F. and Bayerl, T.M. (2005) Differences in the modulation of collective membrane motions by ergosterol, lanosterol, and cholesterol: A dynamic light scattering study. Biophysical Journal, 88, 3360-3367. http://dx.doi.org/10.1529/biophysj.104.050112

[63] Davies, S.S., Pontsler, A.V., Marathe, G.K., Harrison, K.A., Murphy, R.C., Hinshaw, J.C., Prestwich, G.D., Hilaire, A.S.T., Prescott, S.M., Zimmerman, G.M. and McIntyre, T.M. (2001) Oxidized alkyl phospholipids are specific high affinity peroxisome proliferator-activated receptor gamma ligands and agonists. Journal of Biological Chemistry, 276, 16015-16023. http://dx.doi.org/10.1074/jbc.M100878200

[64] Chen, P., Jou, Y.S., Fann, C.S., Chen, J.W., Chung, C.M., Lin, C.Y., Wu, S.Y., Kang, M.J., Chen, Y.C., Jong, Y.S., Lo, H.M., Kang, C.S., Chen, C.S., Chang, H.C., Huangk, N.K., Wu, Y.L. and Pan, W. (2009) Lipoprotein lipase variants associated with an endophenotype of hypertension: Hypertension combined with elevated triglycerides. $\mathrm{Hu}$ man Mutation, 30, 49-55. http://dx.doi.org/10.1002/humu.20812

[65] Hiramoto, M., Yoshida, H., Imaizumi, T., Yoshimizu, N. and Satoh, K. (1997) A mutation in plasma platelet activating factor acetylhydrolase (VAL279-Phe) is a genetic risk factor for stroke. Stroke, 28, 2417-2420. http://dx.doi.org/10.1161/01.STR.28.12.2417

[66] Casas, J.P., Ninio, E., Panayiotou, A., Palmen, J.M., Cooper, J.A., Ricketts, S.L., Sofat, R., Nicolaides, A.N., Corsett, J.P., Fowkes, F.G., Tzoulaki, I., Kumari, M., Brunner, E.J., Kivimak, M., Marmot, M.G., Hoffmann, M.M., Winkler, K., Märtz, W., Ye, S., Stirnadel, H.A., Boekholdt, S.M., Khaw, K.T., Humphries, S.E., Sandhu, M.S., Hinorani, A.D. and Talmud, P.J. (2010) PLA2G7 genotype, lipoprotein-associated phospholipase A2 activity, and coronary heart disease risk in 10494 cases and 15624 controls of European ancestry. Circulation, 121, 2284-2293.

http://dx.doi.org/10.1161/CIRCULATIONAHA.109.9233 $\underline{83}$

[67] Romeo, S., Kozlitina, J., Xing, C., Pertsemlidis, A., Cox, D., Pennachio, L.A., Boerwinkle, E., Cohen, J. and Hobbs, H.H. (2008) Genetic variation in PNPLA3 confess susceptibility to nonalcoholic fatty liver disease. Nature Genetics, 40, 1461-1465.

http://dx.doi.org/10.1038/ng.257

[68] Nelson, M.R., Wegmann, D., Ehm, G.M., Kessner, D., St Jean, P., Verzilli, C., Shen, J., Tang, Z., Bacanu, S., Fraser, D., Warren, L., Aponte, J., Liu, X., Zhang, H., Zhang, Y., Li, Y., Li, L., Woollard, P., Topp, S., Hall, M., Nangle, K., Wang, J., Abecasis, G., Cardon, L., Zöllner, S., Whittaker, J., Chissoe, S., Novembre, J. and Mooser, V. (2012) An abundance of rare functional variants in 202 drug target genes sequenced in 14002 people. Science, 337, 100-104. www.sciencemag.org 